\title{
Investigating the Hofstede's cultural model at the university (Viewpoint of staff and faculty members)
}

\author{
Ehsan Moradi \\ Student of master, university of Sistan and Baluchestan, Zahedan, Iran \\ Mohsen Mohammad Ghasemi \\ Member of Young and Elite Researchers Club, Zahedan, Iran \\ Mohim SheihakiTash, \\ Assistant professor, department of entrepreneurship, university of Sistan and Baluchestan, Zahedan, Iran
}

\begin{abstract}
In recent decade, organizational culture is considered as one of the important issues affecting the human resources' productivity and it has always been a concern for the organizations managers. The organizational culture is the central point of organizational performance. Given the importance of organizational culture, the purpose of this study is to investigate the culture of Islamic Azad University of Zabol according to Hofstede model. This research is descriptive-analytical which its needed data is gathered by distributing the Hofdtede's organizational culture questionnaire amongst 120 staff and faculty members of Zabol IAU. Gathered data was analyzed by SPSS software. The statistical sample was comprised of 30 percent females and 70 percent males. Research findings indicated the cultural balance with a tendency toward masculinity, collectivism, high risk taking, and moderate power distance. In addition, findings indicated that gender affected the organizational culture in such a way that females are more inclined to femininity and males are more inclined to masculinity. Furthermore, the age and job tenure had significant and negative relation with risk taking. According to results, university members approbate the cultural features are close to themselves and believe that the university culture is supportive and fostering. Additionally, they believe that this university tends to avoid injustice in addition to paying attention to social responsibility.
\end{abstract}

Keywords: Organizational Culture; Hofstede's model; Staff and faculty members; Islamic Azad University of Zabol; Gender

\section{Introduction}

In recent decade, organizational culture is considered as one of the important issues affecting the human resources' productivity and it has always been a concern for the organizations managers (Alvani et al., 2012: 25). Culture is a pattern of common assumptions which is learned by group members in such a way that it solves the group's external adaptability and internal coordination issues and is taught to new members as the correct way of understanding and thinking about the problems (schein, 2004). 


\section{$11^{\text {th }}$ International Conference on Modern Research in}

MANAGEMENT, ECONOMICS and ACCOUNTING

\section{8-20 December, 2020 Oxford, United Kingdom}

Human societies have cultures which guide their group actions. One of these human societies is the organization which is defined as the following: "a number of people working together in an organized manner in line with the organizational objectives" (Afjeh, 2001). The organizations are social facilities for controlling and reaching to collective goals and for managing the collective tools. In organizations, employees are influences by dominant values and beliefs which are called as organizational culture. Therefore, organizational culture can be defined as follows: "a set of key values, guidance beliefs, and differences which is common for all the organization members" (Moshabaki, 2001).

Organizational culture is an external variable affecting all the organization members, and thus, proper understanding of this structure is so important for administering the organization and works. Organization members teach the written and even unwritten culture of their organization to newcomers in order to solve the issues relating to external adaptability (e.g., the best way of entering the world markets) and internal integration (e.g., the best way of coordinating the internal processes). Since, we are capable of changing the actions, thoughts, and emotions of organization members through making some changes in organizational culture (Lawson and zang shen: 2002).

In different studies, researchers have tried to know that the people how do look at their organization; if the organization value their creativity and innovation and reward them; and if the organization suppresses the conflicts. Therefore, it can be expected that different people in different organizational levels define the organizational culture using similar statements. While some experts try to define the organizational culture elegantly, some others define it as a type of glue which pastes the organizational parts by common belief patterns. Organizational culture, in a very delicate way, gives the message to its members that what actions are acceptable by the organization.

In studies done by Hofstede (1980) and Schein (1997), culture is comprised of different levels such as main values, norms, beliefs, desires, behaviors, and human artifacts. Because of complicated nature of organizational culture, there is no common framework for identifying and examining it (Ross et al., 2003). However, one of the most common models of identifying and measuring the organizational culture is the Hofstede's model. In Hofstede's opinion, organizational culture is the central point of organizational performance (Hofstede, 1980; McSweeney, 2007).

After studying the branches of IBM Company in 66 countries, Hofstede has developed an experimental model to compare the cultural values of different people (employees and managers). His main theory was that our mind is directly planned when working and learning. The values, norms, attitudes, and behaviors are frequently reflected in the child-parent, studentmaster, employee-employer, and government-citizen relationships. To this purpose, Hofstede conducted an expand survey by distributing 117000 questionnaires translated to 20 different languages which is organized in the years from 1968 to 1972. Each survey was comprised of more than 100 questions about values (Jones, 2007). Based on this research, in 1980, Hofstede 


\section{$11^{\text {th }}$ International Conference on Modern Research in}

MANAGEMENT, ECONOMICS and ACCOUNTING

\section{8-20 December, 2020 Oxford, United Kingdom}

identified four dimensions for organizational culture which include masculinity-femininity, individualism-collectivism, uncertainty avoidance, and power distance (Hofstede, 2003).

Features of Hofstede's organizational culture model reflect the role of organizational culture in the organization efficiency and performance. Therefore, since the universities provide services in the field of education, the current study is to study the organizational culture status of Islamic Azad University of Zabol based on Hofstede's model and the association between demographical variables and Dimensions of Hofstede's organizational culture. Thus, the current study evaluates the organizational culture of Islamic Azad University of Zabol from the viewpoint of faculty members in this university.

\section{Background and importance of research}

Organizational culture is one of the important issues of organizational behavior and many studies have been conducted in this regard.

Alavi and Yadollahi (2003) studies the organizational culture based on Hofstede's model and concluded that there is a negative relationship between femininity and the use of coercive style in treating subordinates.

Mozafari et al. (2008) studies the organizational culture in Iranian universities and found that there is a gap between the ideal and existed culture of faculty members.

Asgarian (1388) studied the concept of organizational culture and indicated that the purpose of explaining the organizational culture is to introduce it to organization members and to create appropriate solutions in order to solve the internal and external problems.

The findings of Sadeghi and lotfolahzadeh (2010) also indicated that low level of uncertainty avoidance is directly related to employees' creativity.

Ghahremani et al. (2010) indicated that there exists a significant relationship between organizational culture and organizational entrepreneurship in Shahid Beheshti University of Tehran.

Sehat et al. (2011) indicated that there exists a significant difference between high- and low-risk insurers in regards to Hofstede's cultural dimensions.

Nejadshekooji and Doaei (2014) investigated the effect of Hofstede's cultural dimensions on customers' trust and indicated that masculinitylfemininity affected the customers' trust in Internet purchasing through their perception of companies' reputation.

Ekrami and Naeimi (2013) estimated each of the cultural dimensions to be more than average and indicated that there is a significant relationship between organizational culture and educational level.

Organizational culture is reinforcement for organizational members and it affects severely all parts of the organization. Thus, it is so important to identify the organizational culture to create an innovative organization and to exploit the employees' creativity (Saeidi, 2010).

After investigating the mentioned studies, it is clear that the organizational culture is an important factor in controlling the organization and improving the organizational culture 


\section{$11^{\text {th }}$ International Conference on Modern Research in}

MANAGEMENT, ECONOMICS and ACCOUNTING

\section{8-20 December, 2020 Oxford, United Kingdom}

directly improves the quality of educational services (Fizi, 2005). And also, one of the newest models of organizational culture is the Hofstede's cultural model. Hofstede believes that the organizational culture is the central point of organizational performance (Hofstede, 1980; McSweeney, 2007). Since the improvement of organizational culture is a very important issue in educational contexts and appropriate planning and management is needed to reach this purpose, the current research is to investigate the organizational culture of Islamic Azad University of Zabol based on Hofstede's model.

\section{Hofstde's model of organizational culture}

Hofstede (1980) indicated that national and local cultural models affect the individuals' behavior in societies and organizations which is constant over time. The Hofstede's classic study about the cultural values especially focuses on social relations and work-related values. He suggests that each person has its own mental programs from their childhood which are reinforced in schools and organizations. These mental programs include the dimensions of national culture, and consequently, social and cultural values and how the works are done differ from one country to another. As follows, he introduces the role of cultural dimensions extracted from IBM-based research that encompasses Iran:

Masculinity-femininity: Managers are aware of this indicator in regards to cultural and competency differences. A masculine society is defined by dominant social values such as this world positions, money, do not like the others, and audacity. In this regard, there are important differences between male and females. Masculinity label indicates that these values are involved with the role of men almost all over the world. In such societies, social roles are severely differentiated based on gender differences. Unlike, feminine societies focus on subtle values in which social affairs (such as individual relations, paying attention to others, quality of life, and services) are more valuable than wealth. In these societies feminine behaviors are considered as a part of females' role.

Collectivism-individualism: In individualist societies, individuals more care about themselves and their families. In these societies, individual entity is so important and individual rights are highly appreciated. Organizational systems try to respect the individuals' priorities and choices, emphasize on individual activities, and reward the employees' performance based on objectives. For instance, in Australia against Japan (collectivist societies) having an individualist value system, it emphasizes on individual activities than group activities. Collectivism-individualism expresses the extent to which people are aware of themselves; it means they find themselves as an independent or member of the group.

Individualist societies intend to individual creativity and achievement, unlike, collectivist societies pay attention to commitments and individuals' loyalty to group (Kamalian and Rashaki, 2015). In collectivist societies, individuals are loyal members of groups or forums and groups support them. In most of the collectivist societies, direct contact with individuals is unpleasant. The word No is rarely used because it is considered as a contact, instead, the 


\section{$11^{\text {th }}$ International Conference on Modern Research in}

MANAGEMENT, ECONOMICS and ACCOUNTING

\section{8-20 December, 2020 Oxford, United Kingdom}

phrases like "you are right" or "we think about it" are politely utilized (Hofstede, 1991). Giving respect to others and paying attention to relatives is of the features of collectivist societies. They believe that they should avoid any changes that may potentially hurt the collectivism values (Beugre and Ofodile, 2001).

Uncertainty avoidance: this indicator refers to consciously avoidance from ambiguous situations which seem to be threatening. Societies of high uncertainty avoidance prefer more structured things and believe that situations should be determined by formal rules and regulations. In these societies, risk taking capability of people is low, they live with high stress, there are many rules and regulations to face with offenders, there is a high concern about security, expert people are highly respected, and individuals' beliefs are based on their expertise and knowledge. Inversely, cultures of low uncertainty avoidance have favorable opinion about unstructured situations. These cultures are highly flexible and uncertainty is accepted as an inevitable issue in life. Individuals are more inclined to take risk, there exist fewer rules as much as possible, beliefs are formed in the framework of a common sense, conflict and competition are mixed with justice and are considered as to be constructive, and experience and knowledge determine the originality.

Power distance: this indicator indicates the extent to which the organizational power is distributed unequally. Features of a society with low power distance are things such as availability of bosses and equal rights of all the people. In societies of high power distance, few numbers of people have independency, hierarchy does mean inequality, bosses are not available, and holders of power have special privileges and immunity. In these societies, subordinates are always faulty and cooperation of people who have not power is unlikely because of their low trust to each other. High power distance is determined with acceptance of unequal power which results in hierarchy in organizations. High power distance in Japan led to a masculine society, but Australian employees do not accept inflexible hierarchical structure (Kamalian and Rashki, 2015).

\section{Method and procedures}

This research is descriptive-analytical and is survey in terms of data gathering method. In this regard, first, theoretical foundations of organizational culture and Hofstede's cultural dimensions are reviewed. Data gathering tool is the Hofstede's organizational culture questionnaire including 25 items ranged on a five-point Likert scale (1=completely disagree, $2=$ disagree, $3=$ no comment, $4=$ agree, $5=$ completely agree). Statistical population is comprised of 120 people in Islamic Azad University of Zabol including 74 employees and 46 faculty members. Sampling method was based on census. Rashedi et al. (2012) have investigated the validity of this questionnaire using Lawshe method and calculated the content validity index of .78. They also investigated its reliability using Cronbach's alpha and reached to the following results for each sub-scales: masculinity-femininity $=.85$, collectivism-individualism $=.72$, uncertainty avoidance $=.78$ and power distance $=.73$. Descriptive statistics were used for 


\section{$11^{\text {th }}$ International Conference on Modern Research in}

MANAGEMENT, ECONOMICS and ACCOUNTING

\section{8-20 December, 2020 Oxford, United Kingdom}

demographic variables and inferential statistics for hypothesis testing. In order to increase the accuracy of calculations, the SPSS software and T- and F-test have been used.

\section{Research results}

\begin{tabular}{|c|c|c|}
\hline \multicolumn{3}{|c|}{ Table 1. The status of organizational culture variables } \\
\hline variable & M & SD \\
\hline Masculinity-femininity & 3.1527 & 0.6369 \\
\hline Individualism / Collectivism & 3.9933 & 0.48917 \\
\hline Uncertainty avoidance & 4.2533 & 0.5679 \\
\hline Power distance & 3.3117 & 0.5847 \\
\hline
\end{tabular}

All the employees and faculty members participated in this research from which 30 percent were females and 70 percent were males. Results indicated a cultural balance inclined to masculinity, collectivism, high uncertainty avoidance, and high power distance.

\begin{tabular}{|c|c|c|c|c|c|}
\hline \multicolumn{2}{|c|}{ Table 2. Mean values for organizational culture variables based on respondents' gender } \\
\hline \multirow{2}{*}{ variable } & \multicolumn{2}{|c|}{ man } & \multicolumn{2}{c|}{ Soman } \\
\cline { 2 - 5 } & $\mathrm{M}$ & $\mathrm{SD}$ & $\mathrm{M}$ & $\mathrm{SD}$ & \\
\hline Masculinity-femininity & 3.3333 & 0.59423 & 2.7311 & 0.52979 & 0.000 \\
\hline Individualism / Collectivism & 4.0238 & 0.49906 & 3.9222 & 0.46421 & 0.299 \\
\hline Uncertainty avoidance & 4.2667 & 0.56852 & 4.2222 & 0.57327 & 0.696 \\
\hline Power distance & 3.319 & 0.6017 & 3.2944 & 0.55081 & 0.834 \\
\hline
\end{tabular}

Results of independent t-test for gender difference between organizational culture variables indicated that the dimension of masculinity-femininity differs between males and females at confidence level of .99. Therefore, females were more inclined to femininity and males were more inclined to masculinity. It means that gender is a factor affecting the organizational culture.

\begin{tabular}{|c|c|c|c|c|c|}
\hline \multicolumn{7}{|c|}{ Table 3. Mean values for organizational culture variables based on respondents' job group } \\
\hline \multirow{2}{*}{ variable } & \multicolumn{2}{|c|}{ sig } \\
\cline { 2 - 5 } & $\mathrm{M}$ & $\mathrm{SD}$ & $\mathrm{M}$ & $\mathrm{SD}$ & \\
\hline Masculinity-femininity & 3.2051 & 0.64771 & 3.0683 & 0.61669 & $\mathbf{0 . 2 5 4}$ \\
\hline Individualism / Collectivism & 3.9964 & 0.42777 & 3.9913 & 0.57959 & $\mathbf{0 . 9 7 2}$ \\
\hline Uncertainty avoidance & 4.2486 & 0.53051 & 4.2609 & 0.62945 & $\mathbf{0 . 9 0 9}$ \\
\hline Power distance & 3.2946 & 0.59355 & 3.3391 & 0.57561 & $\mathbf{0 . 6 8 7}$ \\
\hline
\end{tabular}




\section{$11^{\text {th }}$ International Conference on Modern Research in}

MANAGEMENT, ECONOMICS and ACCOUNTING

\section{8-20 December, 2020 Oxford, United Kingdom}

Results of independent t-test for job group difference between organizational culture variables indicated that there exists no significant difference between the two groups of respondents. It means that job group has no effect on organizational culture.

\begin{tabular}{|c|c|c|c|c|c|c|c|c|c|}
\hline \multicolumn{7}{|c|}{ Table 4. Mean values for organizational culture variables based on respondents' age } \\
\hline \multirow{2}{*}{ variable } & Less than 25 & \multicolumn{2}{c|}{$\mathbf{2 6}$ to 30 } & \multicolumn{2}{c|}{$\mathbf{3 1}$ to 35 } & \multicolumn{2}{c|}{ More than 35 } & Sig \\
\cline { 2 - 9 }$n$ & $\mathrm{M}$ & $\mathrm{SD}$ & $\mathrm{M}$ & $\mathrm{SD}$ & $\mathrm{M}$ & $\mathrm{SD}$ & $\mathrm{M}$ & $\mathrm{SD}$ & \\
\hline $\begin{array}{c}\text { Masculinity- } \\
\text { femininity }\end{array}$ & 3.44 & 0.23215 & 3.0555 & 0.68479 & 3.696 & 0.56216 & 3.3517 & 0.56987 & $\mathbf{0 . 2 0 7}$ \\
\hline $\begin{array}{c}\text { Individualism } \\
\text { / Collectivism }\end{array}$ & 4.1242 & 0.54814 & 4.0545 & 0.44586 & 4 & 0.53475 & 3.9583 & 0.47751 & $\mathbf{0 . 8 9 9}$ \\
\hline $\begin{array}{c}\text { Uncertainty } \\
\text { avoidance }\end{array}$ & 4.6444 & 0.53265 & 4.3273 & 0.55393 & 3.2583 & 0.44998 & 3.1833 & 0.66759 & $\mathbf{0 . 0 0 2}$ \\
\hline $\begin{array}{c}\text { Power } \\
\text { distance }\end{array}$ & 3.5 & 0.35698 & 3.2455 & 0.60374 & 3.375 & 0.61072 & 3.2708 & 0.56605 & $\mathbf{0 . 7 3 7}$ \\
\hline
\end{tabular}

Results of one-way ANOVA for age group difference between organizational culture variables indicated that risk taking differs between age groups at confidence level of .99, so that risk taking is reduced by increasing the age. It means that the age is a factor affecting the organizational culture.

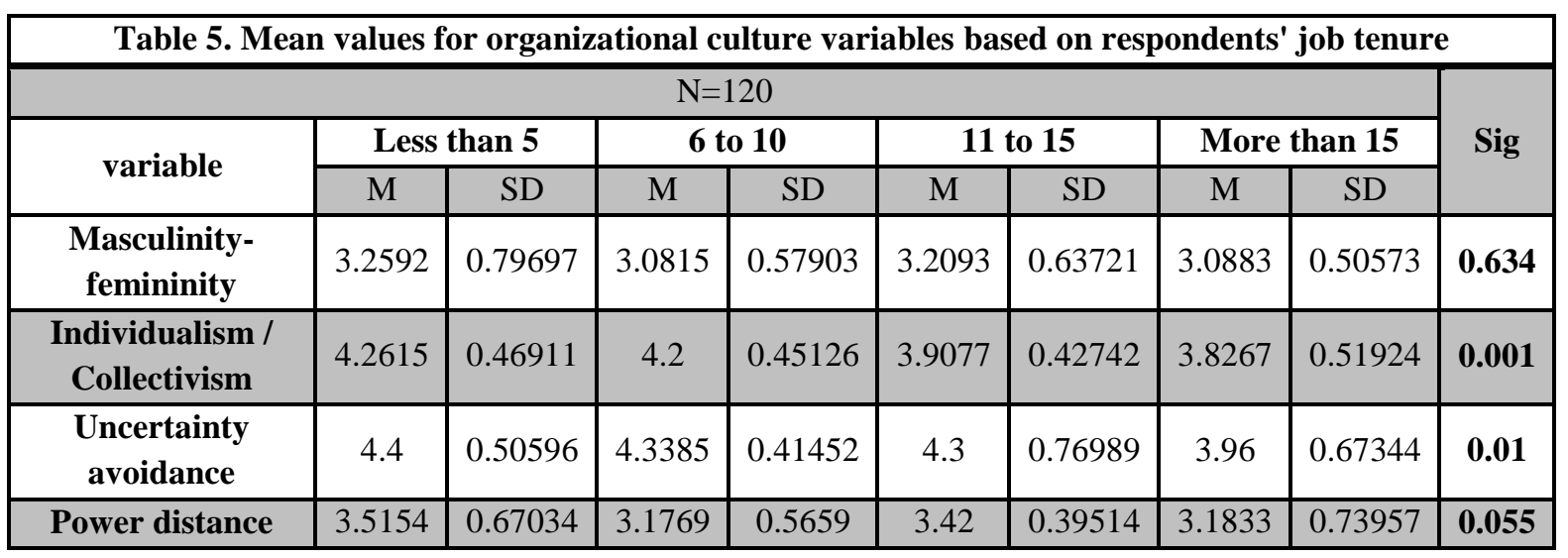

Results of one-way ANOVA for job tenure difference between organizational culture variables indicated that risk taking differs between job tenure groups at confidence level of .99, so that risk taking is reduced by increasing the job tenure. It means that job tenure is a factor affecting the organizational culture.

Table 6. Mean values for organizational culture variables based on respondents' educational level 
$11^{\text {th }}$ International Conference on Modern Research in

MANAGEMENT, ECONOMICS and ACCOUNTING

\section{8-20 December, 2020 Oxford, United Kingdom}

\begin{tabular}{|c|c|c|c|c|c|c|c|c|c|}
\hline \multirow[t]{2}{*}{ variable } & \multicolumn{2}{|c|}{ Diploma } & \multicolumn{2}{|c|}{$\begin{array}{l}\text { Associate } \\
\text { Degree }\end{array}$} & \multicolumn{2}{|c|}{ BS } & \multicolumn{2}{|c|}{$\begin{array}{l}\text { Masters degree } \\
\text { and higher }\end{array}$} & \\
\hline & $\mathrm{M}$ & SD & $\bar{M}$ & SD & $\mathrm{M}$ & SD & $\mathrm{M}$ & SD & \\
\hline $\begin{array}{l}\text { Masculinity- } \\
\text { femininity }\end{array}$ & 3.706 & 0.25233 & 3.306 & 0.48656 & 3.9144 & 0.62921 & 3.1763 & 0.64654 & 0.113 \\
\hline $\begin{array}{c}\text { Individualism / } \\
\text { Collectivism }\end{array}$ & 4.12 & 0.63386 & 4.04 & 0.40879 & 3.9444 & 0.4319 & 3.9938 & 0.51266 & 0.776 \\
\hline $\begin{array}{l}\text { Uncertainty } \\
\text { avoidance }\end{array}$ & 4.2 & 0.53333 & 4.12 & 0.64773 & 4.3444 & 0.52287 & 4.2313 & 0.5901 & 0.651 \\
\hline Power distance & 3.4 & 0.84327 & 3.22 & 0.49171 & 3.2222 & 0.5032 & 3.3625 & 0.59934 & 0.62 \\
\hline
\end{tabular}

Results of one-way ANOVA for educational difference between organizational culture variables indicated that none of the organizational culture variables have significant difference. It means that educational level has no effect on organizational culture.

\section{Conclusion}

Research results indicated a cultural balance inclined to masculinity, collectivism, high uncertainty avoidance, and high power distance. These results indicate that employees and faculty members of Islamic Azad University of Zabol believe that the culture of this university is supportive and fostering. Additionally, they believe that this university tends to avoid injustice in addition to paying attention to social responsibility. These findings are consistent with the findings of Hofstede relating to cultural situation of Iran. In his opinion, after establishment of Islamic regime in January 1979, Iran became similar to other Islamic nations in regards to two variables of uncertainty avoidance and power distance, so that acquired high scores for these two. Additionally, these findings are consistent with the findings of Shahbandarzadeh et al. (2010) in Booshehr University of Medical Sciences, Poorkazemi and Navaei (2004) in University of Tehran, Mohammadi et al. (2010) in Shiraz University, Sorkhabi et al. (2001) in University of Tehran, Rashedi et al. (2012) in Hamedan University of Medical Sciences, and Yaman (2010) in Turkish universities.

According to results, the amount of masculinity-femininity was different between males and females. It means that gender is a factor affecting the organizational culture. Managers are aware of this indicator in regards to cultural and competency differences. A masculine society is defined by dominant social values such as this world positions, money, do not like the others, and audacity. In this regard, there are important differences between male and females. Masculinity label indicates that these values are involved with the role of men almost all over the world. In such societies, social roles are severely differentiated based on gender differences (Kamaliand and Rashki, 2015).

In justifying this finding, given the gender features, it can be said that individuals appreciate those who are similar to themselves which is in line with the study of Rashedi et al. (2012). 


\section{$11^{\text {th }}$ International Conference on Modern Research in}

MANAGEMENT, ECONOMICS and ACCOUNTING

\section{8-20 December, 2020 Oxford, United Kingdom}

According to research results, risk taking of employees and faculty members is reduced by increasing the age and job tenure. This indicator refers to consciously avoidance from ambiguous situations which seem to be threatening. Societies of high uncertainty avoidance prefer more structured things and believe that situations should be determined by formal rules and regulations. In these individuals' beliefs are based on their expertise and knowledge (Dunford, 1992, as cited in Kamaliand and Rashki, 2015). From the signs of low risk taking in organization is that individuals have lower stress. People are less inclined to risk taking by increasing the age and job tenure.

In justifying this finding, it can be said that individuals are willing to more security and survival and less risk and stress by increasing their age and job tenure. This finding is consistent with the findings of Kantek and Baykal (2009), Hofstede (1994), Meeuwesen et al. (2009), and Rashedi et al. (2012).

\section{References}

Alavi Seyed Hemidreza, Yadollahi Hossein ( 2003). Investigating the Culture and Method of Managing Conflicts within the Personnel According to the Hofstede and Thomas Patterns, Social and Humanities Sciences of Shiraz University, Volume 20, Issue 1, Year 39; 81-93.

Alwani, Seyyed Mehdi, Mohammadi, Somayeh and Mirzaie, Mehdi (2013). The Effect of Organizational Culture in the Human Resource Efficiency, Management Quarterly, Year 9, No. 28.

Afjeh, Seyyed Ali Akbar (2001). Philosophical Basics and Theories of Leadership and Organizational Behavior, Tehran: Organization for the Study and Compilation of Humanities Sciences Books.

Asgharian, Mohammad (2009). Conceptualism of Organizational Culture, Human Development of the Police, Volume 6, Number 24; 101 - 124.

Beugre, C.D. \& Ofodile, O.F. (2001) Managing for organizational effectiveness in sub-sahara Africa: A cultural fit model. Internationalhuman resource management.

Dianasi, Feyzi,(2005). Adequate management adapted to the organizational culture of types and changes in culture, translated by Naser Mir Sepasi, Tehran.

Ekraami, Mahmoud, Naeemi Majd, Arezoo (2013).The Development of Knowledge Management Based on Organizational Culture, Innovations in Educational Management (New Thoughts in Educational Sciences), Volume 8, Number 3 (31); 19 - 34. 
$11^{\text {th }}$ International Conference on Modern Research in

MANAGEMENT, ECONOMICS and ACCOUNTING

\section{8-20 December, 2020 Oxford, United Kingdom}

Geert Hofstede TM Cultural Dimensions. Available from: URL: http://geerthofstede.com/iran.html.

ghahremani, Mohammad, pardakhtChi, Mohammad Hassan, Hosseinzadeh, Taher (2010). Organizational Culture and its Relationship with Organizational Entrepreneurship, Perspective of Government Management, Volume 1, Issue 1; 25-39.

Hofstede G.(1994). The business of international, business is culture. International Business Review (14-1) : (1) 3.

Hofstede, Greet. H (1980). Cultures Consequences: International Differences in Work - related Values, Beverly Hills, CA: Sage Publications.

Hofstede G (1980). Motivation, leadership and organization: Do American theories apply abroad. Organizational Dynamics 63-42: (1) 9.

Hofstede G. (2003). What is culture? A reply to Baskerville. Accounting, Organizations and Society 813-811.

Hofstede, G. (1991). Cultures And Organizations: Software of The Mind. Newyork: Mc GrowHill.

Kamalian, Amin Reza and Rashki, Maryam (2013). Management in the field of cultures. Mashhad: Marandiz Publications, Sistan and Baluchestan University.

Kantek RN, Baykal RN (2009). Organizational culture in nursing schools in Turkey: Faculty members > perspectives. International Nursing Review ; (312-306) : (3)56.

Lawson, Robert B. and zang shen ( 2002). Organizational Psychology, Organizational Behavior (Basics and Applications), Translator Ramazan Hasanzadeh, Tehran: Savalan.

McSweeney B.(2007) Hofstede's model of national cultural differences and their consequences: A triumph of faith - a failure of analysis. Human Relations 118-89: (1) 55.

Meeuwesen L, Brink-Muinen A, Hofstede G.(2009). Can dimensions of national culture predict cross-national differences in medical communication? Patient Education and Counseling (66-58) : 75 .

Mohammadi M, Yeganeh EM, Rad TD (2010). The relationship between the faculty members> Perception of organizational culture types and their preferences for instruction and counseling in the Iranian college of education and psychology. Proceedings of Social and Behavioral Sciences 1848-1841. 


\section{$11^{\text {th }}$ International Conference on Modern Research in}

MANAGEMENT, ECONOMICS and ACCOUNTING

\section{8-20 December, 2020 Oxford, United Kingdom}

Moshabaki, Asghar,(2001). Organizational Behavior Management: Applied Analysis, Value of Human Behavior, Tehran: Termeh Publishing Second Printing.

Mozafari Faroogh, pardakhtchee . Mohammad Hassan, Sorkhabee Mohammad, Zokaei Mohammad Saeed.(2008). Investigating the Relationship between Organizational Culture and Leadership Styles in Iranian Universities, Research and Planning in Higher Education, Volume 14, Number 1 (47); 133 - 157.

nejadshokoohi, Fatemeh, doaiee, Habibollah (2014). The effect of Hofstede Cultural Dimensions on the Customer Trust in Internet Shopping with mediation of Customer's Perception from Company,journal Management of Organizational Culture, Volume 12, Issue 1 (2009); 105 - 123.

Pourkazemi MH, Shakeri-Navaei Gh (2004). Investigating the organizational culture of colleges of tehran universities and their role in productivity of colleges. Management Research in Iran (63-37): (27) 36.

Rashed V, Foroughan M, Hosein MA (2012). Correlation between organizational culture and burnout in the staff of the Tehran province welfare organization. Journal of Health Promotion Management (22-15): (2) 1.

Ross BG, Fey C, Denison DR,(2003). Organizational culture and effectiveness: Can the American theory be applied in Russia? Organization Science; 706-686: (6) 14.

Sadeghi Maal Amiri, Mansour, Lotfollahzadeh, Saeed (2010). Investigating the Effect of Organizational Culture on Creativity, Human Development of the Police, Volume 7, Number 29; 105 - 121, June and July.

Saeedi, Parviz ( 2010). Identification of Organizational Culture Based on the Quienn and Garret Model, Quarterly Journal of Educational Psychology, Islamic Azad University, Tonekabon Branch, Year 1, No. 2, Pages 49-59.

Schein, E, H(1997), Organizaitional Culture\& Leadership, zed jossy bass, sanfransisco.

Sehat. Saeed, Mazlumi Nader, Alavi, Seyed Saeed (2011). Hofstede Cultural Dimensions and the Number of Damages in Third-Party Car Insurance, Insurance Research journal (Insurance Industry), Volume 26, Issue 1 (Summer 101), 87 - 107.

Shahbandarzaeh H, Mohammadi-Yeganeh R, Hasanpour, N (2010). Evaluation of the organizational culture of the police and its comparison with the university, finance, and shipbuilding organization: a competing values model. Journal of order and security forces; 52-31: (1) 3. 
$11^{\text {th }}$ International Conference on Modern Research in MANAGEMENT, ECONOMICS and ACCOUNTING

\section{8-20 December, 2020 Oxford, United Kingdom}

Shine, Edgar,( 2004). Management of Organizational Culture and Leadership, Translation of Borzou Farahi Bozanjani and Shamsodin Noori Najafi, Tehran: Young face, First Printing.

Sorkhabi M, Pardakhtchi MH, Torabikia H (2001). Relationship between organizational culture and job satisfaction of faculty members of Tehran University. Humanities Alzahra University: 304-277 ; (39) 11.

Yaman E (2010). Perception of faculty members exposed to mobbing about organizational culture and climate. Educational Sciences: Theory \& Practice 578-567: (1) 10. 